\title{
Redescripción de Tityopsis aliciae (Scorpiones: Buthidae)
}

\section{Redescription of Tityopsis aliciae (Scorpiones: Buthidae)}

\author{
Vianey Vidal-Acosta ${ }^{1}$ y Oscar F. Francke ${ }^{2 *}$ \\ ${ }^{1}$ Laboratorio de Entomología, Instituto de Diagnóstico y Referencia Epidemiológicos, Centro Nacional de Vigilancia Epidemiológica y Control de \\ Enfermedades, Secretaria de Salud, Prol. de Carpio 470, Col. Santo Tomás, 11340 México D.F., México. \\ ${ }^{2}$ Colección Nacional de Arácnidos, Departamento de Zoología, Instituto de Biología, Universidad Nacional Autónoma de México, Apartado postal \\ 70-153, 04510 México, D.F., México. \\ *Correspondencia: offb@ibiologia.unam.mx
}

\begin{abstract}
Resumen. Se redescribe Tityopsis aliciae Armas y Martín-Frías, 1998 con base en una hembra adulta de la localidad tipo, Tehuantepec, Oaxaca. El holotipo, único ejemplar conocido previamente, es una hembra subadulta en muy mal estado de conservación, lo cual ocasionó imprecisiones en la descripción original. Existían ciertas dudas acerca de la veracidad de la procedencia del holotipo, pero el hallazgo de una hembra adulta de la misma especie ratifica la presencia de este género, el segundo de la familia Buthidae en México.
\end{abstract}

Palabras clave: alacranes, México, Oaxaca, neobotriotaxia.

\begin{abstract}
Tityopsis aliciae Armas y Martín-Frías, 1998 is redescribed based on an adult female from the type locality, Tehuantepec, Oaxaca. The holotype, previously the only known specimen, is a subadult female and it is poorly preserved, which led to some inaccuracies in the original description. There were some doubts regarding the type locality, but the finding of an adult female confirms the presence of this genus, the second belonging to the family Buthidae, in Mexico.
\end{abstract}

Key words: Scorpions, Mexico, Oaxaca, neobothriotaxia.

\section{Introducción}

El género Tityopsis Armas, 1974 tiene 3 especies: T. inexpectata (Moreno, 1940) y T. inaequalis (Armas, 1974) del occidente de Cuba; y T. aliciae Armas et Martín-Frías, 1998, de Oaxaca, México. Tityopsis aliciae fue descrita con base en un sólo ejemplar hembra, mal preservado, dañado y malformado, supuestamente colectado en Tehuantepec en julio de 1938. Dicha situación ocasionó que se dudara de la validez de dicha especie, así como de la presencia del género en México. El segundo autor estudió minuciosamente el holotipo de T. aliciae en el 2005 y concluyó que podría tratarse de un ejemplar juvenil, mal etiquetado, del género Alayotityus Armas, 1973, conocido con base en 4 especies del oriente de Cuba. Sin embargo, recientemente se tuvo acceso a un segundo ejemplar de T. aliciae, una hembra adulta también procedente de Tehuantepec, Oaxaca, motivo de la presente redescripción, que nos permite determinar que el holotipo de T. aliciae no es un ejemplar adulto, y confirmar la presencia del género Tityopsis en México. La familia Buthidae está representada en México por 2 géneros.

Recibido: 16 junio 2008; aceptado: 03 octubre 2008

\section{Materiales y métodos}

El ejemplar se estudió, midió y dibujó con un microscopio Zeiss Stemi SV 6 con reglilla micrométrica en oculares de $10 \mathrm{X}$ y con una cámara clara. Las fotografías de habitus se tomaron con una cámara digital Nikon D 100, lente Micro-Nikkor (55 mm 1:2.8) con proyección de luz blanca. Las microfotografías se tomaron con una cámara Nikon Coolpix S10 acoplada a un microscopio estereoscópico Nikon SMZ 650. Se tomaron las mediciones y se usó la nomenclatura de acuerdo con Stahnke (1970), excepto la nomenclatura tricobotrial (Vachon 1974, 1975) y la de las carenas del metasoma (Francke, 1977).

\section{Descripciones}

Diagnosis. Alacrán pequeño, hembra adulta $29,5 \mathrm{~mm}$ (Cuadro1), de color café claro, con 9 hileras de gránulos en el borde interno de los dedos de la quela del pedipalpo (las 2 especies cubanas tienen 13 hileras) y una hilera corta apical de 4 gránulos en el dedo móvil. Dientes pectíneos 8-9. Tubérculo subaculear muy desarrollado en forma de trapecio en vista lateral (las 2 especies cubanas carecen 
Cuadro 1. Medidas (en $\mathrm{mm}$ ) de las hembras de Tityopsis aliciae Armas y Martín-Frías, 1998

\begin{tabular}{lcc}
\hline & Adulta & Holotipo \\
\hline Longitud total & 29.5 & 21.7 \\
Longitud carapacho & 3.5 & 2.7 \\
Longitud mesosoma & 9.7 & 6.4 \\
Longitud metasoma & 13.3 & 10.1 \\
I Segmento (largo/ancho) & $2.0 / 1.7$ & $1.5 / 1.4$ \\
II Segmento & $2.4 / 1.6$ & $1.9 / 1.3$ \\
III Segmento & $2.7 / 1.7$ & $2.0 / 1.3$ \\
IV Segmento & $2.9 / 1.7$ & $2.2 / 1.3$ \\
V Segmento & $3.3 / 1.6$ & $2.5 / 1.3$ \\
Longitud del telson & 3.0 & 2.5 \\
Longitud vesícula & 1.8 & 1.6 \\
Ancho vesícula & 1.3 & 1.1 \\
Profundidad vesícula & 1.3 & 1.0 \\
Longitud aguijón & 1.2 & 0.9 \\
Longitud pedipalpo & 11.4 & 9.3 \\
Longitud fémur & 2.8 & 2.3 \\
Ancho fémur & 1.0 & 0.8 \\
Longitud patela & 3.2 & 2.6 \\
Ancho patela & 1.2 & 1.0 \\
Longitud quela & 5.4 & 4.4 \\
Ancho quela & 1.7 & 1.1 \\
Profundidad quela & 1.6 & 1.1 \\
Longitud dedo móvil & 3.0 & 2.7 \\
Longitud dedo fijo & 2.5 & 2.3 \\
Dientes pectinales (izq.-der.) & $9-8$ & $8-8$ \\
\hline
\end{tabular}

de espina o tubérculo subaculear). Mesosoma con franja longitudinal media oscura. Terguitos III-VII con carena mediana corta, poco marcada; sin carenas paramedianas. Terguito VII con carenas paramedianas y laterales con gránulos grandes, bien desarrolladas. Tricobotriotaxia A-alfa, reductiva en 3 artejos del pedipalpo: fémur sin $d_{2}$, patela $\sin d_{2}$, quela $\sin E b_{3}$ (las especies cubanas son ortobotriotáxicas, presentando $d_{2}$ en el fémur y en la patela y $E b_{3}$ en la quela).

Redescripción basada en una hembra adulta (Figs.1-5, 1012).

Coloración general (Figs. 1, 2): región dorsal café clara, jaspeada con café oscuro bajo los gránulos mayores. Base de los dedos café rojiza. Quelíceros color crema, dientes café rojizos. Región ventral y patas café claro, pardo. Peines color crema.

Prosoma. Carapacho (Fig. 3) tan largo como ancho (ancho posterior), densamente cubierto con gránulos de tamaño pequeño a grande; margen anterior bilobulado con pocas sedas cortas de punta roma y con gránulos grandes, la hendidura media es poco profunda y tiene una abertura de 90 grados aproximadamente; además posee 2 gránulos grandes, fusionados, rojizos debajo de la base de la hendidura; márgenes laterales con gránulos pequeños y finos desde la altura donde inician las carenas supraciliares hasta el borde posterior; carenas supraciliares y posteriores medias bien desarrolladas, gránulos pequeños alrededor del área de los ojos medios y en todo el surco medio posterior; con 3 ojos laterales anteriores izquierdos y 2 ojos laterales anteriores derechos; relación longitud del carapacho/ longitud del V segmento del metasoma: 1,14. Esternón subtriangular más ancho que largo, con 1 cavidad media posterior; margen anterior con 1 escotadura en la parte media, cubierto con gránulos que descienden por la base de la escotadura rodeando la cavidad media posterior y con 2 pares de sedas con punta roma una basal y otra apical (Fig. 4).

Mesosoma. Terguitos granulados con gránulos de tamaño grande a lo largo del borde posterior, carena mediana longitudinal con gránulos moderados, obscura; preterguitos con gránulos pequeños. En el terguito I, preterguito con gránulos pequeños pigmentados en la parte media y poco manchados hacia la parte lateral. En los terguitos II-VI, preterguitos con gránulos pequeños pigmentados forman 1 mancha negra media y 2 laterales. En el terguito VII, preterguito con gránulos pequeños pigmentados formando 1 mancha en la parte media, y adicionales en las regiones laterales. Manchas medias de los terguitos I-VII forman 1 franja longitudinal media, débil. Posterguitos con gránulos pequeños en la parte anterior y con gránulos de mediano tamaño en la parte posterior. Terguitos I-IV con el borde posterior pigmentado. Terguito VII con carenas paramedianas y laterales granulares, espacios intercarinales con gránulos de tamaño grande y mediano. Peines con 9-8 dientes; lámina basal no engrosada, rectangular, con el borde posterior ligeramente curvo y con gránulos pequeños en el borde posterior (Fig. 4); amplia área central despigmentada, aparentemente no esclerosada y que podría corresponder a una glándula exocrina [como el androvestigio de los machos de algunos Brachistosternus Thorell (Bothriuridae) y Hadrurus Thorell (Iuridae)]. Esternitos densa y finamente granulosos, con gránulos de moderado tamaño. Esternito III con una protuberancia en forma de $\mathrm{V}$ invertida en la parte media posterior, en la zona distal media de la protuberancia se encuentra una área blanquecina (Fig. 4), las áreas laterales del segmento presentan depresiones profundas. Esternitos IV-V con un par de carenas incipientes. Esternito VI con 2 pares de carenas, siendo las paramedianas más débiles. Esternito VII con 2 pares de carenas bien desarrolladas, el par de carenas paramedianas llegando al borde posterior. Estigmas pulmonares pequeños, arriñonados. 

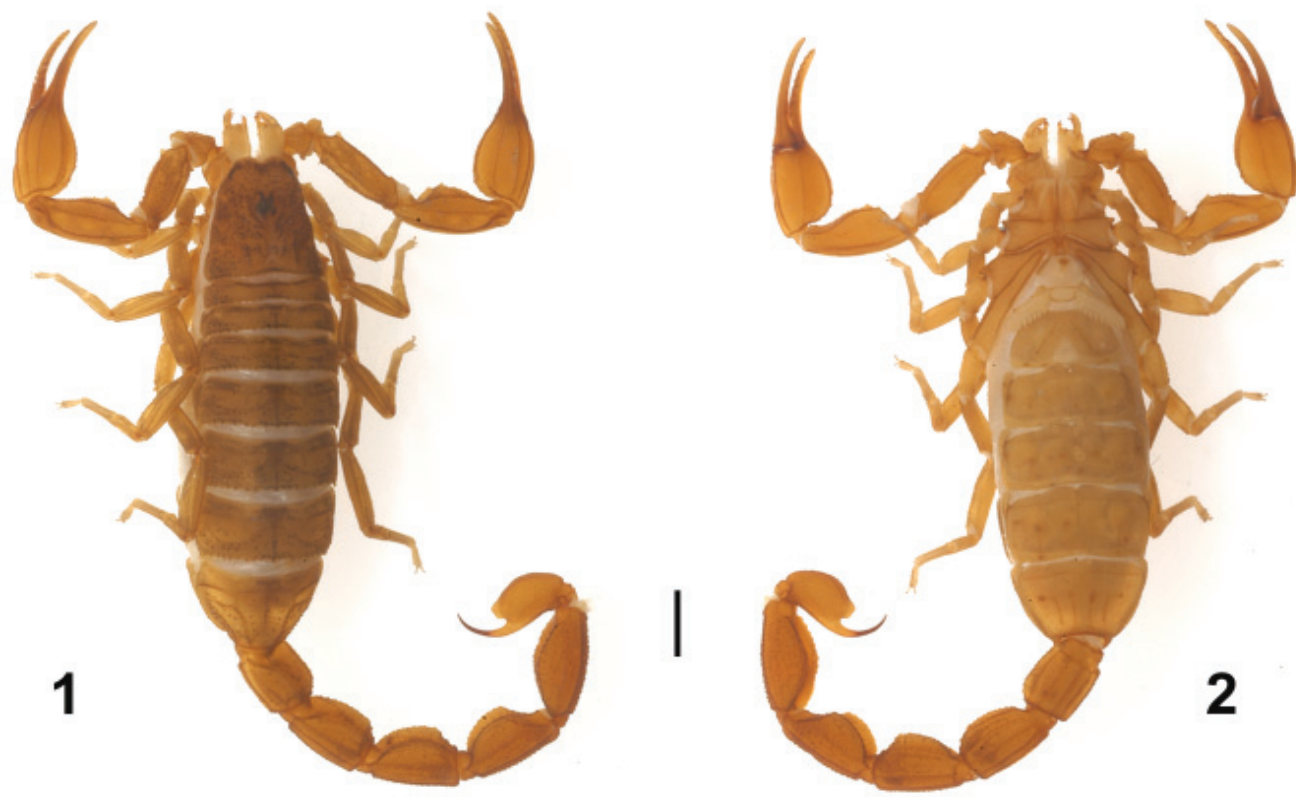

Figuras 1-2. Tityopsis aliciae, hembra adulta. 1 , vista dorsal; 2 , vista ventral (escala $=2$ $\mathrm{mm})$.
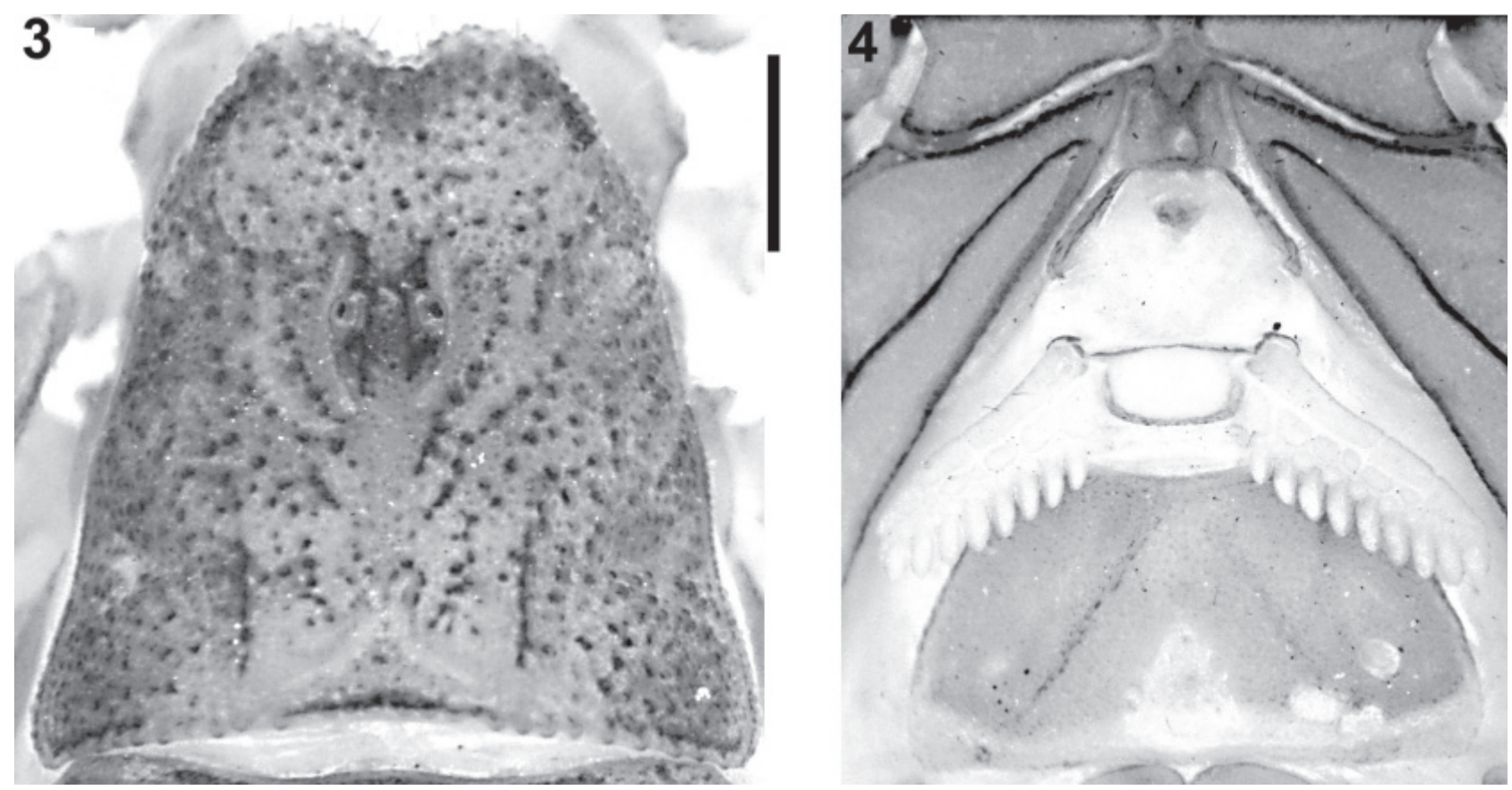

Figuras 3-4. Tityopsis aliciae, hembra adulta. 3, carapacho; 4, vista ventral del esternón, opérculo genital, peines y esternito III (escala $=1 \mathrm{~mm}$ ).

Metasoma. Segmentos I-II con 10 carenas, segmentos III-IV con 8 carenas. Carenas dorsolaterales en I-V fuertes, subaserradas en I-III y subdentadas en IV-V. Carenas laterales supramedianas y laterales inframedianas subaserradas, moderadas y granulosas en I-II; carenas laterales supramedianas subaserradas, fuertes y granulosas en III-IV. Carenas ventrolaterales y ventrales submedianas subaserradas, fuertes y granulosas en I-IV. Segmento $\mathrm{V}$ con carenas laterales supramedianas inconspicuas, subdentadas; carenas ventrolaterales subaserradas fuertes y granulosas; carenas ventrales submedianas aserradas, fuertes, bien desarrolladas iniciando desde el borde 

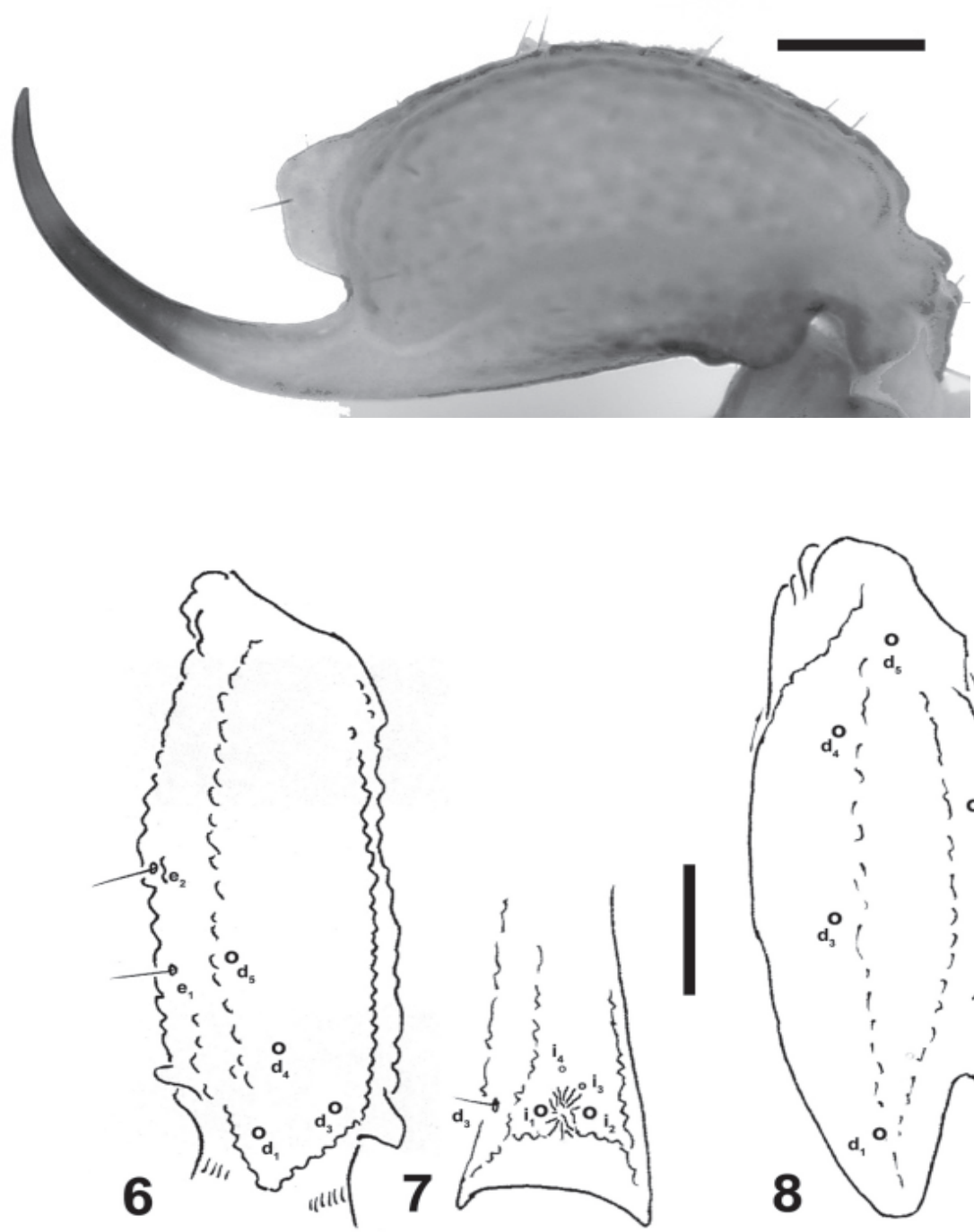
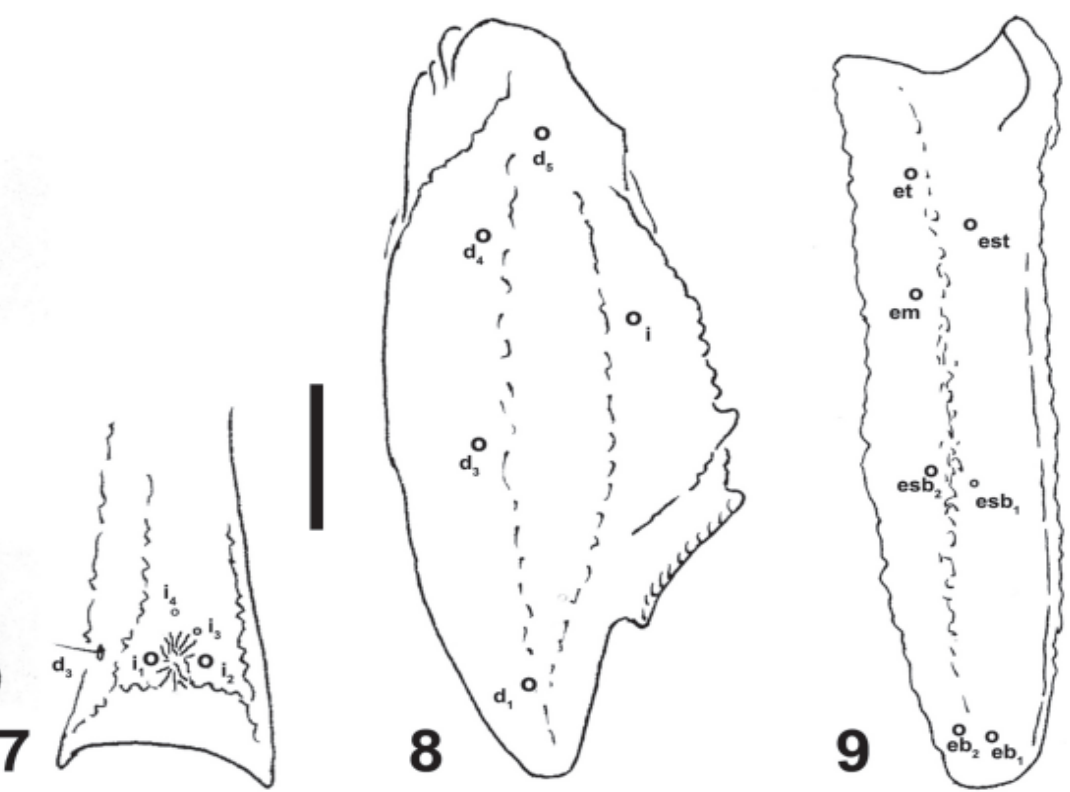

Figuras 6-9. Tityopsis aliciae, patrón tricobotrial del holotipo, hembra subadulta. 6, fémur izquierdo, vista dorsal; 7, detalle de la cara interna del fémur; 8 , patela izquierda, vista dorsal; 9, patela izquierda, cara externa (escala $=0.5 \mathrm{~mm}$ ).

basal del segmento hasta un poco más allá de la mitad, terminando cada una con 1 seda corta de punta roma; carena ventromediana aserrada, fuerte, bien desarrollada. Espacios intercarinales moderadamente granulosos con gránulos de tamaño pequeño, mediano y grande. Segmentos III-V ventralmente con escasas sedas cortas de punta roma.

Telson. Vesícula moderadamente globosa, superficies ventrales y laterales moderadamente granulosas con escasas sedas cortas de punta roma, tubérculo subaculear muy conspicuo, en forma de trapecio en vista lateral (Fig. 5). Aguijón con longitud de 2/3 la longitud de la vesícula, muy curvado, con su ápice alcanzando el nivel del borde
Figura 5. Tityopsis aliciae, hembra adulta; telson mostrando tubérculo subaculear trapezoidal (escala $=0.5$ $\mathrm{mm})$. ventral de la vesícula (Fig. 5).

Patas. Sin espolones tibiales; con espolones tarsales interno y externo en todas las patas. Telotarsos ventralmente sin fila de espinulas media; con 7-8 pares de sedas lateroventrales.

Quelíceros. Dedo fijo con 1 diente ventral; dedo móvil con 2 dientes ventrales.

Pedipalpos. Fémur: carenas dorsal interna, dorsal externa y ventral interna bien desarrolladas y dentadas, carena ventral externa bien desarrollada y subaserrada, la carena media externa se extiende distalmente más allá de la tricobotria $e_{2}$, carena media interna dentada se extiende desde el borde basal hasta cerca del borde distal, con 


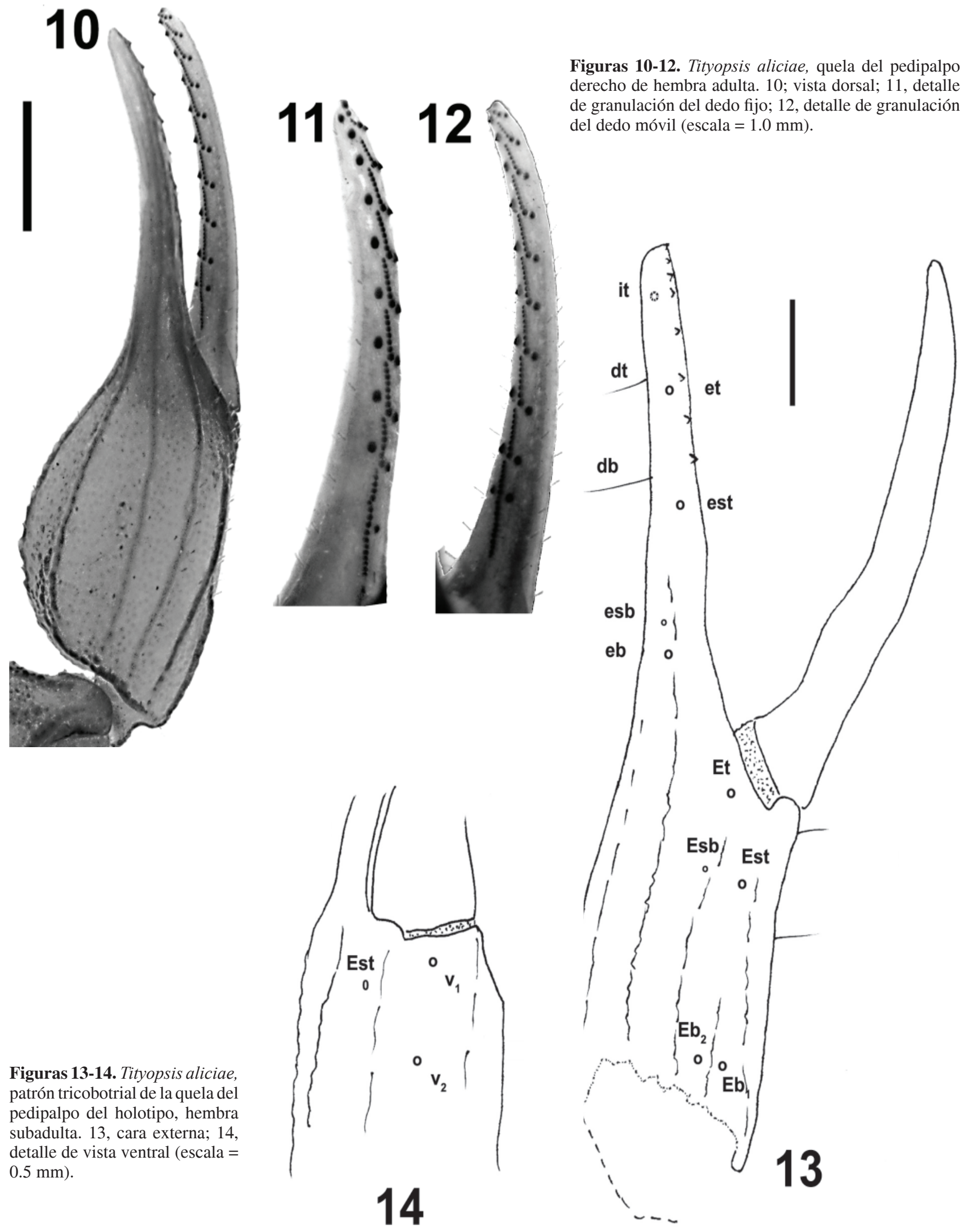


gránulos grandes y chicos intercalados. En la cara interna entre las tricobotrias $I_{1}-I_{4}$ e $I_{2}-I_{3}$ se encuentra un pequeño tubérculo con el borde granulado. Todas las caras del fémur con gránulos pequeños y medianos, y con escasas sedas cortas gruesas rosadas de punta roma. Neobotriotaxia reductiva "A-alpha" (Vachon, 1975), faltando la $d_{2}$ (Figs. 6 y 7). Patela: carenas dorsal interna y dorsal externa bien desarrolladas, dentadas; dorsal media bien desarrollada dentada; carena ventral interna bien desarrollada, dentada, la parte basal subaserrada; ventral externa bien desarrollada, con gránulos cónicos y entre ellos gránulos más pequeños redondos, con la parte basal aserrada; externa media muy desarrollada y subdentada formando un borde. Todas las caras de la patela con gránulos pequeños y medianos y con escasas sedas cortas gruesas, rosadas y de punta roma. Neobotriotaxia reductiva "A" (Vachon, 1974), faltando la $d_{2}$ (Figs. 8 y 9). Quela (Fig. 10): mano con carena ventro externa bien desarrollada, subdentada; carena interna media bien desarrollada, incompleta, sin llegar a la articulación del dedo móvil, parte basal con gránulos cónicos o subaserrada; carena ventrointerna bien desarrollada, subdentada; carena marginal dorsal bien desarrollada, aserrada en la parte basal subdentada en el resto; carena secundaria dorsal bien desarrollada subdentada; carena digital bien desarrollada, subdentada; carena secundaria externa bien desarrollada, subdentada; carena externa dorsal bien desarrollada, subdentada sin alcanzar la base de la articulación del dedo móvil; carena externa media bien desarrollada, subdentada, presente sólo en el tercio basal de la mano; todas las caras de la mano con gránulos pequeños y medianos, con escasas sedas cortas gruesas rosadas y de punta roma. Dedo fijo con 9 hileras oblicuas de gránulos (Fig. 11), dedo móvil con 9 hileras oblicuas de gránulos más 1 hilera apical corta de 4 gránulos (Fig. 12), con gránulos supernumerarios internos y externos. Dedos lisos, sin gránulos, con sedas cortas, gruesas, rosadas y de punta roma, distribuidas en todos sus lados; con escasas sedas cortas, delgadas, blanquecinas distribuidas sobre todo en la parte interna; lóbulo basal moderado. Neobotriotaxia reductiva "A" (Vachon, 1974), faltando la $E b_{3}$ (Figs. 13 y 14).

Material tipo. Holotipo hembra (subadulta), Tehuantepec, Oaxaca, México, 30 de julio de 1938, depositado en la Colección Nacional de Arácnidos (CNAC-T0173), Instituto de Biología, Universidad Nacional Autónoma de México. Examinado; en mal estado de conservación, ya que aparentemente estuvo seco por algún tiempo, está fragmentado y descolorido, y muchos detalles no se aprecian con claridad. La quela del pedipalpo derecho está fragmentada en su base y falta un pedazo de cutícula basal, lo que dificulta apreciar el patrón tricobotrial completo; la quela del pedipalpo izquierdo presenta una deformación teratológica y carece de muchas tricobotrias.

Material adicional examinado. Hembra adulta colectada en Santo Domingo Tehuantepec $\left(16.31^{\circ} \mathrm{N}-95.23^{\circ} \mathrm{O}\right)$, Oaxaca, dirección Cima \# 61, bajo tejas, 12 de enero del 2006; colector desconocido. Se realizó una colecta manual diurna. La identificación fue realizada por la primera autora. El ejemplar será depositado en la Colección de Artrópodos con Importancia Médica (CAIM) del Laboratorio de Entomología del InDRE de la Secretaría de Salud.

Distribución. Sólo se conoce de la localidad tipo.

Variación. El holotipo es menor que la hembra adulta descrita en esta contribución (Cuadro 1) y presenta 88 dientes pectíneos contra 9-8. El patrón tricobotrial, la dentición de los dedos de los pedipalpos y las carenas del metasoma son iguales en ambos ejemplares.

\section{Comentarios taxonómicos}

La descripción original indica que T. aliciae es ortobotriotáxico, razón por la cual sospechamos que la especie fue incluida dentro de dicho género. Sin embargo, ese no es el caso, ya que los 2 ejemplares conocidos presentan neobotriotaxia reductiva en los 3 artejos del pedipalpo: fémur $\sin d_{2}$, patela $\sin d_{2}$ y quela $\sin E b_{3}$. El género Alayotityus presenta neobotriotaxia reductiva en el fémur y la patela; en algunas especies del género la quela del pedipalpo es ortobotriotáxica, y en otras es neobotriotáxica, faltando la tricobotria $e s b$; razón por la cual el segundo autor inicialmente sospechó que el holotipo de T. aliciae podría ser un ejemplar de Alayotityus mal etiquetado. Alayotityus se caracteriza, entre otros, por tener 3 quillas longitudinales en los terguitos; el mal estado de preservación del holotipo de T. aliciae no permite apreciar con claridad ese carácter. Sin embargo, el nuevo ejemplar claramente presenta una sola carena media en los terguitos I a VI. Recientemente, el segundo autor colectó en Guerrero una especie cercana a T. aliciae. La descripción de dicha especie está en preparación; en ese trabajo se examinarán las relaciones filogéneticas de las especies mencionadas.

\section{Agradecimientos}

A Herón Huerta y a Isaac A. Enríquez Monsalvo por el apoyo recibido durante las mediciones, a Edgar $\mathrm{S}$. Marín Suro por las fotografías del ejemplar completo, a Alejandro Valdéz Mondragón por las microfotografías y a Carlos Santibáñez-López por el apoyo en la preparación de las ilustraciones y la lectura crítica del manuscrito; a los 
entomólogos de campo del Istmo de Tehuantepec, Oaxaca, por la atinada recolecta y a Jorge Martínez Muñoz por la adecuada preservación del ejemplar. A Rolando Teruel, por la donación de ejemplares de Alayotityus a la CNAN, el constructivo intercambio de ideas y observaciones, y por la revisión minuciosa del manuscrito. La primera autora agradece también a Sergio Ibáñez Bernal por haberla iniciado en el estudio de los alacranes.

\section{Literatura citada}

Armas, L. F. de y E. Martín-Frías. 1998. Presencia del género Tityopsis en México y descripción de una especie nueva
(Scorpiones: Buthidae). Anales de la Escuela Nacional de Ciencias Biológicas 43:45-49.

Francke, O. F. 1977. Scorpions of the genus Diplocentrus from Oaxaca, Mexico. Journal of Arachnology 4:145-200.

Stahnke, H. L. 1970. Scorpion nomenclature and mensuration. Entomological News 81:297-316.

Vachon, M. 1974. Étude de caractéres utilisés pour classer les familles et les genres de scorpions (Arachnides). Bulletin du Muséum National d’Historie Naturelle, sér. 3 104:857958.

Vachon, M.1975. Sur l'utilisation de la trichobothriotaxie du bras des pédipalpes des Scorpions (Arachnides) dans le classement des genres de la familla des Buthidae Simon. Comptes Rendus Academie de Sciences, sér. D 281:15971599. 